\title{
Reativação do Perímetro Irrigado de Gravatá: Uma abordagem otimizante sobre agricultura irrigada e sustentabilidade hídrica
}

\author{
Cícero A. G. Lima ${ }^{1}$, Wilson F. Curi ${ }^{2} \&$ Rosires C. Curi ${ }^{3}$
}

\begin{abstract}
RESUMO
Neste trabalho se analisa a possibilidade de reativação do Perímetro Irrigado de Gravatá, com uma área potencial de 934 ha, localizado na bacia do Rio Piancó, no sudoeste do Estado da Paraíba. Com tal objetivo utilizaram-se o modelo de otimização ORNAP, para seleção, alocação de área e demandas hídricas mensais das culturas e o modelo de simulação MODSIM P32 para verificação da sustentabilidade hídrica dos reservatórios Canoas e Saco de Nova Olinda, responsáveis pelo suprimento de água para o perímetro; depois se avaliou o comportamento hídrico do sistema, através de análises, para diversos cenários climáticos e de volumes iniciais nos reservatórios considerando-se um horizonte de planejamento de dois anos. O estudo mostrou que, com as mudanças propostas no plano de cultivo e no sistema de irrigação e se utilizando de modelo de alocação otimizada de água através de um plano de operação dos reservatórios, é possível, mesmo em condições climáticas e de volumes iniciais nos reservatórios desfavoráveis, irrigar até $70 \%$ da área potencial do referido perímetro.
\end{abstract}

Palavras-chave: otimização, operação de reservatórios, irrigação

\section{Reactivation of the Irrigated Perimeter of Gravatá: An optimization approach to irrigated agriculture and water sustainability}

\begin{abstract}
This work is concerned with the possibility of reactivation of Irrigated Perimeter of Gravatá, with potential land availability of 934 ha, which is located at Piancó river basin in the southern part of Paraiba State. To perform the analysis, the ORNAP optimization model was used to allocate optimal irrigated areas to a pre-selected set of crops, as well as their water requirement, and the MODSIM P32, a simulation model, was used to verify the water sustainability of Canoas and Saco de Nova Olinda reservoirs, which supply water. The hydro behavior of system was verified through the design of scenarios for climatic and initial volumes for the reservoirs, taking into account a planning time horizon of two years. The results have shown that up to $70 \%$ of the available land can be irrigated, even with unfavorable climatic conditions and initial reservoir volumes, if an optimized crop scheduling and irrigation selection, as well as reservoir water allocation, is performed.
\end{abstract}

Key words: optimization, reservoir operation, irrigation

\footnotetext{
1 Pesquisador CCT/UFCG. Rua Cassimiro de Abreu 250, Ed. Pagannini, Ap. 808, Jardim Luna, CEP 58033-330, João Pessoa, PB. Fone: (83) $3244-1562$. E-mail: ciceroglima@hotmail.com

2 UAF/UFCG. Rua Aprígio Veloso 882. Bodocongó, CEP 58109-970, Campina Grande, PB. Fone: (83) 3310-1195. E-mail: wfcuri@pesquisador.cnpq.br

3 AUEL/UFCG. Fone: (83) 3310-1290. E-mail: rosirescuri@pesquisador.cnpq.br
} 


\section{INTRODUÇÃO}

A alocação e o gerenciamento dos recursos hídricos para usos múltiplos envolvem, freqüentemente, disputa entre diversos interesses. Nota-se evidência de que o mundo enfrenta, hoje, uma séria crise relacionada com a questão dos recursos hídricos, devido não apenas à má distribuição espaço-temporal das precipitações mas, também, a uma falta de gerenciamento adequado, sobretudo nas regiões com escassez desses recursos.

A diversificação do uso da água e o conseqüente aumento da demanda, originaram o problema de demandas conflitantes. Segundo Lanna (1997), esses conflitos podem ser: conflitos de destinação de uso, conflitos de disponibilidades quantitativas e/ou qualitativas. Em regiões semi-áridas, como é o caso do Nordeste do Brasil, o gerenciamento racional e otimizado da água passa a ser absolutamente imprescindível, face às peculiaridades climáticas e ambientais que condicionam as atividades humanas e o desenvolvimento social da região (Vieira, 1996).

Dentro desse contexto se insere a região objeto deste estudo, isto é, a bacia hidrográfica do Rio Piancó, localizada à sudoeste da Paraíba, região semi-árida do Estado, na qual se observa intenso conflito de uso da água, de caráter interestadual (Lima, 2004). Nela está localizada a maior reserva hídrica do Estado, o sistema de reservatórios Coremas-Mãe D’Água, com capacidade de acumulação de aproximadamente 1,4 bilhões de metros cúbicos, responsável pelo suprimento das demandas hídricas das Várzeas de Sousa, pelo abastecimento de várias localidades e, principalmente, pela perenização do rio Piancó, principal afluente do Piranhas-Açu, por onde é liberada a vazão para suprir as demandas de água do vizinho Estado do Rio Grande do Norte, objeto de conflito entre os dois estados. A bacia do rio Piancó detém um grande potencial de área irrigável no estado, na qual existem dez projetos públicos de irrigação que, juntos, totalizam aproximadamente 7.000 ha, dentre os quais se encontra o perímetro Gravatá, foco deste trabalho. Apesar desse potencial de área agricultável, menos de $10 \%$ dessa área estava sendo efetivamente explorada. Segundo a Secretaria Extraordinária do Meio Ambiente, Recursos Hídricos e Minerais do Estado (SEMARH), se encontra, aliada à falta de investimento em infra-estrutura, linhas de crédito etc, como causa da desativação de alguns projetos de irrigação na bacia do Piancó, a falta de um plano de cultivo consistente e de sistemas de irrigação mais eficientes, que permitam o uso otimizado dos recursos hídricos das fontes de suprimento dos respectivos perímetros irrigados.

Dentre os sistemas eficientes a irrigação por aspersão é um dos métodos mais utilizados devido à sua versatilidade, facilidade de manejo e à possibilidade de aplicação a quase todo tipo de cultura, solo e topografia. Segundo Vermeiren \& Jobling, citados por Gomes (1999), no sistema por gotejamento, método de alta freqüência no qual a água é aplicada diretamente sobre a zona radicular da planta, observa-se uma economia de água, em geral entre 20 e 30\%, podendo atingir até $60 \%$ em culturas frutíferas com gran- de espaçamento, com relação ao sistema por aspersão.

Este estudo é de suma importância para a região do Vale do Piancó, no tocante a dois aspectos: socioeconômico e o uso racional da água. No primeiro aspecto, o estudo apresenta uma proposta concreta para reativação do perímetro, através de mudança no plano de cultivo e nos sistemas de irrigação atuais; de forma a se obter maiores receitas líquidas com uso da mão-de-obra local, com geração de mais empregos e aquecimento da economia da região. No segundo aspecto, o estudo aborda o uso racional e sustentável das disponibilidades hídricas dos reservatórios, através da utilização de um modelo de otimização, visando à obtenção de maiores receitas líquidas advindas da agricultura irrigada e da piscicultura, com a alocação otimizada de água para a irrigação.

Com o objetivo de compartilhar a oferta e a demanda hídrica e a utilização racional da água propõe-se, neste trabalho, a utilização de um modelo de otimização para dar suporte ao gerenciamento dos recursos hídricos, visando suprir as demandas para a irrigação de uma área de 934 ha do projeto Gravatá.

\section{MATERIAL E MÉTODOS}

Realizou-se, para o estudo da reativação do perímetro de irrigação Gravatá, um estudo da sustentabilidade das fontes hídricas, no tocante ao suprimento das demandas do referido perímetro, através de simulações hídricas dos reservatórios Canoas e Saco de Nova Olinda. Essas simulações foram realizadas de forma contínua, com a utilização da série pseudo-histórica de 57 anos de vazões afluentes, no módulo planejamento tático, para o horizonte de planejamento de dois anos e simulações para os cenários climáticos de dois anos: seco e normal, cenários climáticos alternados e combinações entre eles. Estudou-se, ainda, o comportamento hídrico do sistema considerando-se diferentes volumes iniciais nos reservatórios, de forma a se analisar as reais condições de sustentabilidade hídrica do sistema para a reativação do perímetro estudado. Para determinação das demandas hídricas das culturas foi utilizado o modelo de otimização ORNAP (Curi \& Curi, 2001) e, para as simulações do sistema de reservatórios, o modelo MODSIM P32 (Labadie, 1989).

\section{Localização do Perímetro Irrigado de Gravatá}

O Perímetro Irrigado de Gravatá está localizado nos municípios de Nova Olinda e Pedra Branca, com uma área potencial de 934 ha, que se estende ao longo das margens do rio Gravatá. O abastecimento hídrico do perímetro é constituído de uma barragem de derivação interligada ao reservatório Canoas, através de um canal (Canoas) e ao reservatório Saco de Nova Olinda, através do rio Gravatá, de onde parte o canal principal Gravatá, com capacidade para transportar uma vazão de $2,3 \mathrm{~m}^{3} \mathrm{~s}^{-1}$ responsável pela adução de água da barragem até o perímetro. A Figura 1 mostra a localização e o sistema hídrico do perímetro estudado. 


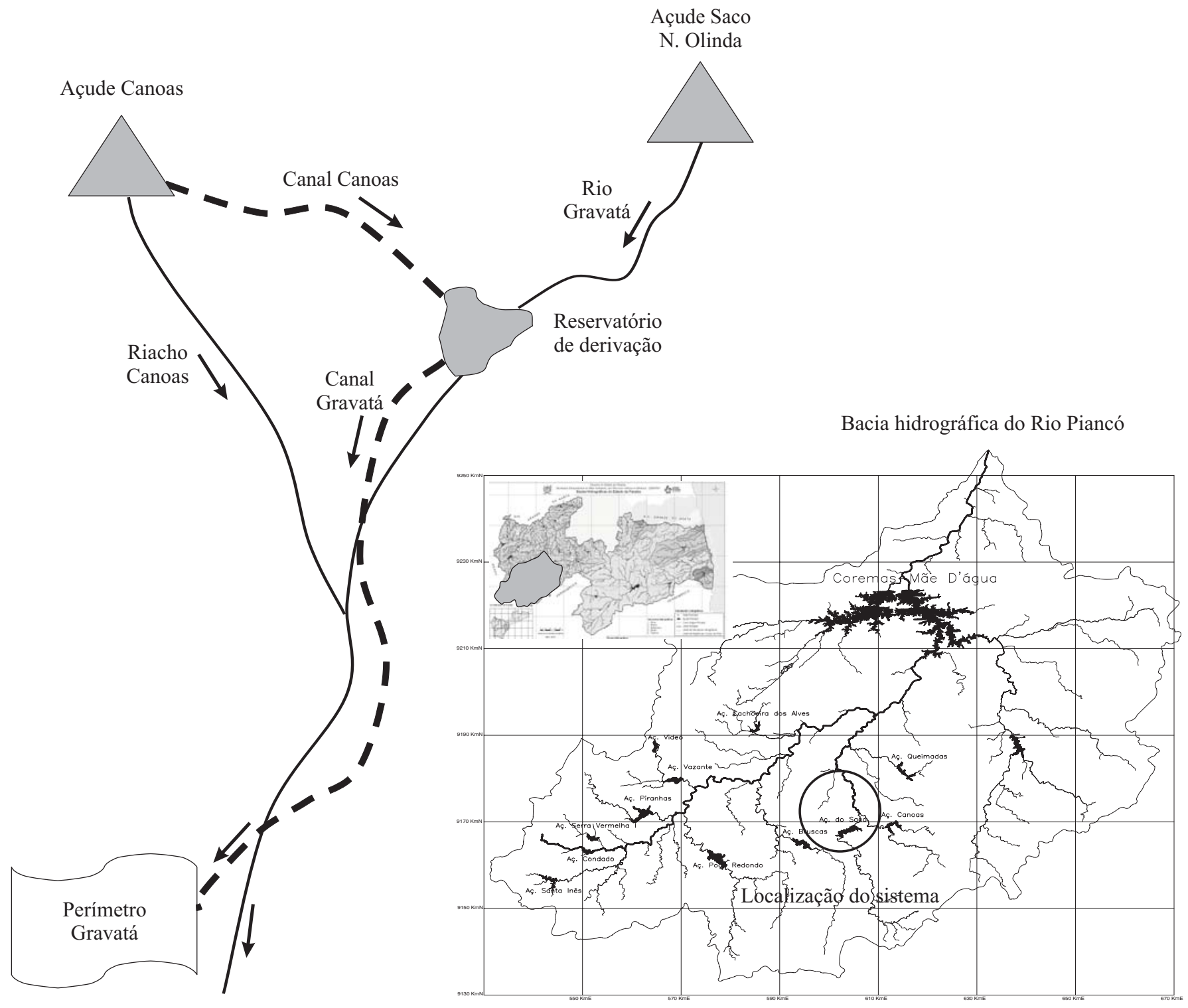

Figura 1. Localização e esquema do sistema hídrico do Perímetro Irrigado de Gravatá

\section{Fatores climáticos, classes e usos do solo}

A região da bacia hidrográfica estudada se encontra, segundo a classificação climática de Köeppen, na região tropical úmido (Aw’i), com estação seca no outono e baixa variação de temperatura ao longo do ano.

Os principais solos encontrados na região do perímetro irrigado Gravatá, são: Bruno Não Cálcico $\left(\mathrm{NC}_{1}\right.$ e $\left.\mathrm{NC}_{2}\right)$, inseridos na classe IV de capacidade de uso e Aluvissolo Eutrófico $\left(\mathrm{Ae}_{1} \mathrm{a} \mathrm{Ae}_{13}\right)$, inserindo-se na classe III de capacidade de uso.

\section{Fonte hídrica e sistema de irrigação}

A fonte hídrica que alimenta o Perímetro Irrigado Gravatá é composta de dois reservatórios: Canoas, com capacidade máxima de acumulação de $46,6 \mathrm{hm}^{3}$, e Saco de Nova Olinda, com capacidade de acumulação de $97,5 \mathrm{hm}^{3}$, este último responsável também pelo abastecimento do município de Nova Olinda.

Os sistemas de irrigação projetados originalmente para o perímetro, com as respectivas áreas de irrigação, foram: aspersão convencional (106,10 ha), Sulco (569,65 ha), inundação (190,42 ha) e rizicultura (81,97 ha); desses sistemas, o único mantido na proposta apresentada neste estudo foi o sistema por aspersão convencional, visto que os outros sistemas são ultrapassados e demandam grandes quantidades de água.

\section{O modelo de otimização ORNAP}

Utilizou-se, para maximização das receitas líquidas advindas da agricultura irrigada do perímetro Gravatá, o modelo ORNAP (Curi \& Curi, 2001), o qual possui relações funcionais não lineares, tanto a nível de função objetivo como das restrições, que são resolvidas numericamente através da programação não linear.

Os dados relacionados aos elementos naturais utilizados, foram: hidroclimáticos (precipitação, evaporação, vazões afluentes), hidroagrícolas (coeficiente de cultivo, produtividade, necessidade hídrica, custo de produção) e hidráulicos 
(capacidade do reservatório, dados das tomadas d’água, vertedores). O período computacional do modelo é mensal para os doze meses do ano. A função objetivo permite a aferição de desempenho do modelo para inúmeras restrições, que são representadas por equações de natureza linear e não linear. Essas equações traduzem, a nível mensal: as limitações físicas dos reservatórios, dos perímetros irrigados e dos equipamentos hidráulicos e também as limitações hidrológicas, inerentes aos sistemas de usos múltiplos da água.

O uso deste modelo teve como objetivos, selecionar e calcular as áreas a serem irrigadas para as culturas previstas para o perímetro estudado, de forma a maximizar a receita líquida advinda da agricultura irrigada. A receita líquida é entendida como o resultado da diferença entre a renda bruta total auferida com a venda da safra agrícola e os respectivos custos de produção envolvidos, gerada pela escolha apropriada pelo modelo, das áreas a serem irrigadas.

\section{O modelo de simulação MODSIM P32}

O modelo MODSIM P32 foi desenvolvido no Colorado State University, por Jonh Labadie, em 1989 tem, como suposição básica, que o sistema de recursos hídricos possa ser representado como Rede de Fluxo. O modelo é capaz de gerar planos operacionais a fim de satisfazer metas, prioridades e limitações específicas, além de ser de fácil adaptação a diversos tipos de problemas, de tal forma que a maior parte das configurações e estruturas operacionais das bacias hidrográficas possa ser representada por meio de especificação de dados de entrada. São atributos importantes do modelo:

- simular a rede de fluxo de volumes armazenados em reservatórios e distribuir as vazões em sistema complexo de recursos hídricos em uma bacia hidrográfica;

- otimizar, a nível mensal, a operação de sistemas, mediante a utilização de um algoritmo de rede de fluxo, chamado out-of-kilter (OKM), algoritmo de programação linear primal-dual, desenvolvido especialmente para a solução eficiente de problemas de minimização de custos em redes de fluxo;

- formular diretrizes operacionais de curto (semanal) ou de longo prazo (sazonal ou plurianual);

- ser um instrumento de gerenciamento, que pode ser usado também para o planejamento, para a análise de impacto de propostas alternativas para implantação de projetos de aproveitamento de recursos hídricos.

A utilização do modelo MODSIM P32 objetivou a simulação integrada dos reservatórios com vistas às análises de sustentabilidade hídrica para a alocação de água e o atendimento às demandas de abastecimento e irrigação estabelecidas para o sistema, considerando-se diversos cenários de afluência hídrica e volumes iniciais nos reservatórios. O esquema para o sistema hídrico do perímetro Gravatá utilizado para a simulação, está representado na Figura 2.

A partir das demandas hídricas para a irrigação, obtidas do modelo de otimização (ORNAP), efetuaram-se simulações com uso do modelo MODSIM P32, de acordo com o enfoque (tipo de cálculo) e cenários climáticos estabelecidos. Dois tipos de cálculos foram utilizados para a análise da sustentabilidade hídrica do sistema:

- Simulação contínua: teve, como objetivo, a análise do comportamento hídrico do sistema com base na série pseudo-histórica de vazões afluentes aos reservatórios.

- Planejamento tático: teve, como objetivo, a análise das estatísticas referentes às probabilidades de falha dos reservatórios no atendimento às demandas, no horizonte de planejamento de 2 anos, considerando a série de 57 anos de vazões afluentes.

Com a finalidade de verificar qual seria a área mínima para a irrigação das culturas perenes capaz de ser suprida pelo sistema de reservatórios com sustentabilidade hídrica, realizou-se simulação no sistema para o cenário climático adverso, no caso ano seco; para a avaliação das possibilidades de irrigar áreas adicionais (relativas às culturas sazonais), o sistema foi simulado para o cenário climático normal, cujas definições estabelecidas para o estudo foram:

- Cenário climático seco: considerado o ano mais severo, em termos de afluência hídrica aos reservatórios, observado na série de 57 anos de vazões pseudo-históricas afluentes aos reservatórios.

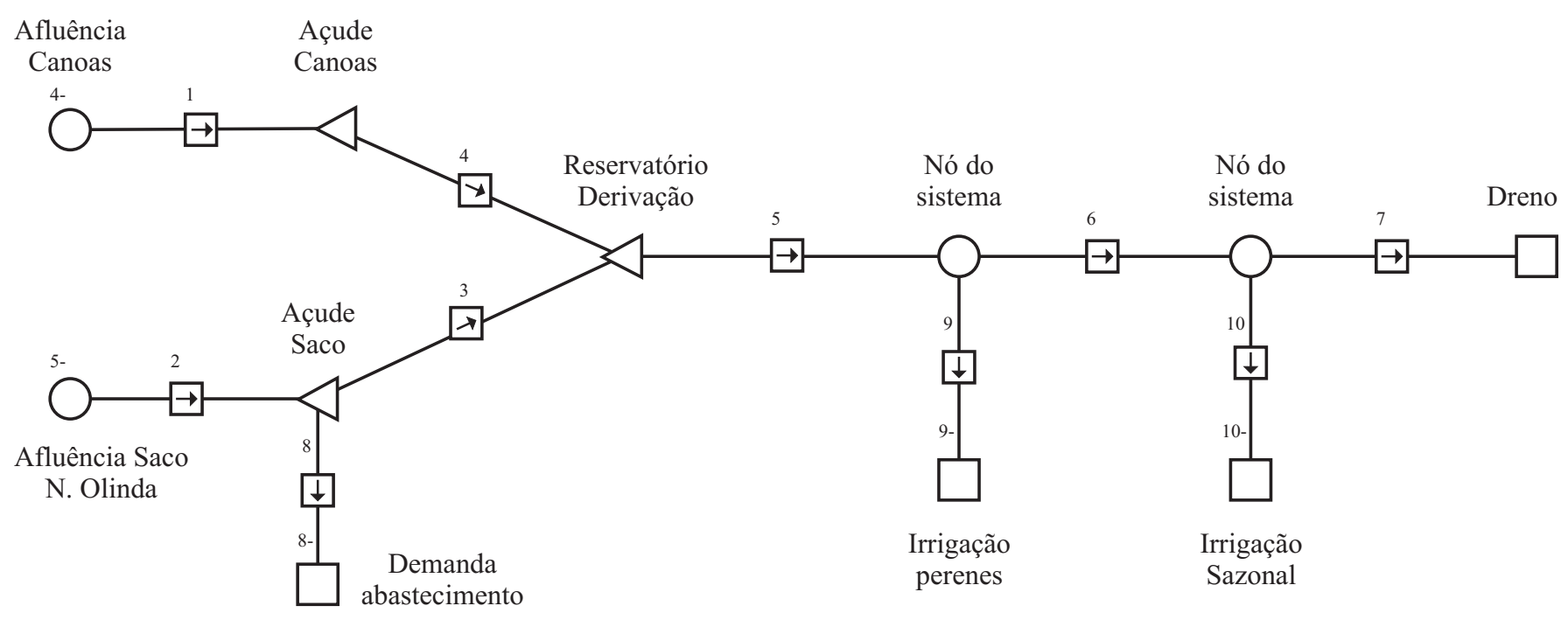

Figura 2. Esquema para simulação do sistema hídrico no modelo MODSIM P32 
- Cenário climático normal: considerado a média da série de 57 anos de vazões pseudo-históricas afluentes aos reservatórios.

Em função da variabilidade temporal das precipitações na região estudada, foi também avaliado o comportamento hídrico do sistema, considerando-se cenários climáticos alternados, ou seja, combinações entre os cenários climáticos: um ano seco seguido de um ano normal e um ano normal seguido de um ano seco. Nessas combinações, as simulações dos reservatórios foram realizadas para diferentes percentuais de volumes iniciais, variando entre 30 e $40 \%$ das suas capacidades máximas.

\section{Volume de alerta}

Como forma de garantir o atendimento das demandas de abastecimento urbano e as demandas hídricas de irrigação para as culturas perenes, durante um ano climático seco, estabeleceu-se o volume de alerta de $20 \mathrm{hm}^{3}$, ou seja, volume mínimo a ser mantido no sistema dos reservatórios Canoas e Saco de Nova Olinda, a partir do qual o suprimento hídrico para as culturas sazonais seria suspenso.

\section{Dados das culturas}

As culturas agrícolas selecionadas para o perímetro estudado, tiveram como base dois aspectos: aptidão agrícola, segundo os estudos de viabilidade do projeto e mudanças nos sistemas de irrigação inicialmente indicados para o projeto
Gravatá. Neste estudo, foram selecionadas nove culturas, sendo que as culturas temporárias foram consideradas na safra (período chuvoso) e entressafra (irrigados). Somente o plantio de arroz foi considerado de sequeiro, ou seja, no período chuvoso, visto que seu retorno financeiro não é viável com cultivo irrigado, em virtude do grande consumo de água que esta cultura demanda.

O modelo de otimização utilizado considera distintas as culturas nas situações de plantio de sequeiro e irrigado, devido às variações nos valores de custo de produção, preço de venda, uso da água dos reservatórios etc, sendo, portanto, catorze o número total de culturas considerado pelo modelo. $\mathrm{Na}$ Tabela 1 estão listadas as culturas selecionadas e os respectivos valores dos coeficientes de cultivos e, na Tabela 2, os dados de produtividade média, custo de produção, trabalho requerido e custo com mão-de-obra; para os valores de preço unitário de venda das culturas no período de safra e entressafra, foram considerados os preços médios de mercado.

\section{Plano de cultivo e sistema de irrigação propostos}

Para o estabelecimento das áreas mínimas e máximas para plantio de cada cultura, foram alocados os seguintes percentuais: $30 \%$ para as culturas sazonais e $70 \%$ para as culturas perenes. A alocação de uma área maior para as culturas perenes teve, como base, a maior receita líquida auferida com sua agricultura irrigada; na Tabela 3 estão apresentados o

Tabela 1. Distribuição dos coeficientes de cultivo $\left(\mathrm{Kc}^{\prime} \mathrm{s}\right)$ das culturas selecionadas

\begin{tabular}{|c|c|c|c|c|c|c|c|c|c|c|c|c|}
\hline \multirow{2}{*}{ Tipos de cultura } & \multicolumn{12}{|c|}{ Meses do ano hidrológico } \\
\hline & Jan & Fev & Mar & Abr & Mai & Jun & Jul & Ago & Set & Out & Nov & Dez \\
\hline \multicolumn{13}{|c|}{ Sazonais } \\
\hline Algodão (herbáceo 8H) & - & 0,45 & 0,75 & 1,15 & 0,75 & - & - & 0,45 & 0,75 & 1,15 & 0,75 & \\
\hline Feijão (Macaçar) & - & 0,70 & 1,10 & 0,90 & - & - & - & 0,75 & 1,15 & 0,80 & & \\
\hline Milho (Doce) & - & 0,75 & 1,07 & 1,00 & - & - & - & 0,75 & 1,07 & 1,00 & 0,70 & \\
\hline Arroz & - & 1,10 & 1,10 & 1,10 & 1,10 & - & - & - & - & - & - & \\
\hline Melancia & - & - & - & 0,65 & 0,95 & 0,83 & 0,75 & - & 0,65 & 0,95 & 0,83 & 0,75 \\
\hline Tomate & - & - & - & 0,45 & 0,75 & 1,15 & 0,80 & - & 0,45 & 0,75 & 1,15 & 0,80 \\
\hline \multicolumn{13}{|c|}{ Perenes } \\
\hline Banana (Pacovan) & 1,10 & 1,10 & 1,10 & 1,0 & 1,10 & 1,10 & 1,10 & 1,10 & 1,10 & 1,10 & 1,10 & 1,10 \\
\hline Graviola & 0,65 & 0,65 & 0,65 & 0,65 & 0,65 & 0,65 & 0,65 & 0,65 & 0,65 & 0,65 & 0,65 & 0,65 \\
\hline Coco (Anão) & 0,75 & 0,75 & 0,75 & 0,75 & 0,75 & 0,75 & 0,75 & 0,75 & 0,75 & 0,75 & 0,75 & 0,75 \\
\hline
\end{tabular}

Fonte: Engenharia de Irrigação: hidráulica dos sistemas pressurizados. Aspersão e gotejamento (Gomes, 1999)

Tabela 2. Produtividade média, custo médio de produção, trabalho requerido e custo médio para as culturas selecionadas

\begin{tabular}{|c|c|c|c|c|c|c|c|c|}
\hline \multirow{2}{*}{ Tipos de cultura } & \multicolumn{2}{|c|}{ Produtividade média $\left(\mathrm{kg} \mathrm{ha}^{-1}\right)$} & \multicolumn{2}{|c|}{ Custo de produção (R\$ ha-1) } & \multicolumn{2}{|c|}{ Trabalho requerido (diária ha-1) } & \multicolumn{2}{|c|}{ Custo mão de obra (R\$ ha-1) } \\
\hline & Safra & Entressafra & Safra & Entressafra & Safra & Entressafra & Safra & Entressafra \\
\hline \multicolumn{9}{|c|}{ Sazonais } \\
\hline Algodão & 1.200 & 2.000 & 971,60 & $1.268,00$ & 104 & 119 & 558,00 & 613,00 \\
\hline Feijão & 800 & 1200 & 513,00 & 908,00 & 31 & 56 & 248,00 & 448,00 \\
\hline Milho & 1.500 & 8.000 & 513,00 & $1.017,00$ & 55 & 62 & 240,00 & 516,00 \\
\hline Arroz & 1.500 & - & 4763,00 & - & 66 & - & 528,00 & - \\
\hline Tomate & 24.000 & 40.000 & $2.860,00$ & $3.596,00$ & 212 & 262 & $1.696,00$ & $2.016,00$ \\
\hline Melancia & 15.000 & 25.000 & $1.435,00$ & $2.422,00$ & 90 & 115 & 720,00 & 920,00 \\
\hline \multicolumn{9}{|c|}{ Perenes } \\
\hline Banana & - & 26.500 & - & $3.185,00$ & - & 198 & - & $1.565,00$ \\
\hline Graviola & - & 6.500 & - & $2.060,00$ & - & 113 & - & 903,00 \\
\hline Coco & - & 32.500 & - & $1.317,00$ & - & 105 & 836,00 & - \\
\hline
\end{tabular}


Tabela 3. Plano de cultivo proposto para o perímetro

\begin{tabular}{|c|c|c|c|c|c|c|c|c|c|c|c|c|c|c|}
\hline \multirow{2}{*}{$\begin{array}{l}\text { Tipos de } \\
\text { cultura }\end{array}$} & \multirow{2}{*}{$\begin{array}{l}\text { Época de } \\
\text { plantio }\end{array}$} & \multicolumn{12}{|c|}{ Meses do ano hidrológico } & \multirow{2}{*}{$\begin{array}{c}\text { Sistema de irrigação } \\
\text { proposto }\end{array}$} \\
\hline & & A & S & 0 & N & D & $\mathbf{J}$ & $F$ & M & A & M & $J$ & $J$ & \\
\hline \multicolumn{15}{|c|}{ Cultivares sazonais } \\
\hline Algodão & safra & & & & & & & & & & & & & Aspersão \\
\hline & entressafra & & & & & & & & & & & & & Convencional \\
\hline Feijão & safra & & & & & & & & & & & & & Aspersão \\
\hline & entressafra & & & & & & & & & & & & & Convencional \\
\hline Milho & safra & & & & & & & & & & & & & Aspersão \\
\hline & entressafra & & & & & & & & & & & & & Convencional \\
\hline Arroz & safra & & & & & & & & & & & & & - \\
\hline Tomate & safra & & & & & & & & & & & & & Microaspersão \\
\hline & entressafra & & & & & & & & & & & & & Aspersão conv. \\
\hline Melancia & safra & & & & & & & & & & & & & Microaspersão \\
\hline & entressafra & & & & & & & & & & & & & Aspersão conv. \\
\hline \multicolumn{15}{|c|}{ Cultivares perenes } \\
\hline Banana & & & & & & & & & & & & & & Microaspersão \\
\hline Graviola & contínua & & & & & & & & & & & & & Aspersão conv. \\
\hline Coco & & & & & & & & & & & & & & \\
\hline
\end{tabular}

plano de cultivo anual e os respectivos sistemas de irrigação propostos para o perímetro Gravatá.

Na otimização do sistema foram considerados dois tipos de sistema de irrigação: aspersão convencional (sistema fixo) e microaspersão. O sistema por gotejamento não foi levado em conta em razão da textura arenosa do solo, que demandaria um consumo maior de água que o sistema por microaspersão. Os custos de implantação desses sistemas obtidos no mercado, foram: R 2.000,00 ha-1 (aspersão convencional) e R\$ 3.500,00 ha-1 (microaspersão), ambos com vida útil estimada em 10 anos.

\section{Dados climáticos}

Obtiveram-se os dados de precipitação sobre o lago dos reservatórios do posto pluviométrico de Nova Olinda (3843992) e os dados de evaporação do Tanque Classe "A" e da Estação Climatológica de Coremas. A Tabela 4 mostra os valores médios de precipitação e evaporação utilizados nas simulações dos reservatórios.

As séries pseudo-históricas de vazões afluentes aos reservatórios foram obtidas do modelo MODHAC, versão aperfeiçoada MOHTSAR, Modelo Hidrológico para o Trópico Semi-Árido, disponível no Plano Diretor da Bacia do Rio
Piancó (SCIENTEC, 1997).

\section{Dados dos reservatórios}

Os dados utilizados nos modelos de otimização e simulação, foram: as equações de ajuste das curvas cota $\mathrm{x}$ área $\mathrm{x}$ volumes dos reservatórios, obtidas com o uso do software LabFit (Silva \& Silva, 2003) e os parâmetros relacionados aos reservatórios, apresentados na Tabela 5. Ressalta-se que o reservatório Canoas não se encontra concluído e o volume indicado na referida tabela representa uma estimativa da sua capacidade atual.

\section{Demandas hídricas}

A demanda hídrica mensal para o abastecimento do município de Nova Olinda foi adotada como $10 \mathrm{l} \mathrm{s}^{-1}$, com base em dado fornecido pela Companhia de Água e Esgotos da Paraíba (CAGEPA); atualmente, esta demanda é suprida pelo reservatório Saco de Nova Olinda.

Para obtenção das demandas mensais de irrigação, direcionadas para as culturas perenes e sazonais, utilizou-se o modelo de otimização ORNAP (Curi \& Curi, 2001). A separação das demandas por tipo de cultura teve como objetivo priorizar o atendimento às demandas das culturas perenes, em

Tabela 4. Dados médios mensais de precipitação e evaporação

\begin{tabular}{|c|c|c|c|c|c|c|c|c|c|c|c|c|}
\hline \multirow{2}{*}{ Dados } & \multicolumn{12}{|c|}{ Valores médios mensais (mm) } \\
\hline & Jan & Fev & Mar & Abr & Mai & Jun & Jul & Ago & Set & Out & Nov & Dez \\
\hline Precipitação & 85 & 143 & 235 & 171 & 69 & 31 & 11 & 5 & 2 & 12 & 24 & 31 \\
\hline Evaporação & 272 & 215 & 204 & 182 & 183 & 182 & 220 & 272 & 300 & 333 & 319 & 311 \\
\hline
\end{tabular}

Tabela 5. Dados dos reservatórios do sistema estudado

\begin{tabular}{|c|c|c|c|c|c|c|c|c|c|}
\hline \multirow{3}{*}{ Reservatórios } & \multicolumn{2}{|c|}{ Volume máximo Volume mínimo } & \multicolumn{4}{|c|}{ Tomada d'água } & \multicolumn{3}{|c|}{ Vertedor } \\
\hline & \multirow{2}{*}{\multicolumn{2}{|c|}{$\left(\mathrm{hm}^{3}\right)$}} & \multirow{2}{*}{ Coef } & \multirow{2}{*}{$\begin{array}{c}\text { Dâmetro } \\
(\mathrm{mm})\end{array}$} & \multirow{2}{*}{$\begin{array}{c}\text { Seção } \\
\left(\mathrm{m}^{2}\right)\end{array}$} & \multirow{2}{*}{$\begin{array}{l}\text { Cota } \\
\text { (m) }\end{array}$} & \multirow[t]{2}{*}{ Coef. } & Largura $(\mathrm{m})$ & Soleira (m) \\
\hline & & & & & & & & \multicolumn{2}{|c|}{$(\mathrm{m})$} \\
\hline Canoas & 10,00 & 0,45 & 0,80 & 500 & 0,20 & 235 & 0,49 & 120 & 365 \\
\hline Saco de N. Olinda & 97,49 & 8,83 & 0,80 & 500 & 0,20 & 352 & 0,49 & 45 & 377 \\
\hline
\end{tabular}


Tabela 6. Demandas hídricas mensais para a irrigação

\begin{tabular}{|c|c|c|c|c|c|c|c|c|c|c|c|c|}
\hline \multirow{2}{*}{$\begin{array}{l}\text { Tipos de } \\
\text { cultura }\end{array}$} & \multicolumn{12}{|c|}{ Valores médios mensais $\left(\mathrm{m}^{3} \mathrm{~s}^{-1}\right)$} \\
\hline & Jan & Fev & Mar & Abr & Mai & Jun & Jul & Ago & Set & Out & Nov & Dez \\
\hline Perenes & 0.27 & 0.07 & 0.00 & 0.01 & 0.16 & 0.23 & 0.32 & 0.41 & 0.46 & 0.51 & 0.45 & 0.40 \\
\hline Sazonais & 0.00 & 0.00 & 0.00 & 0.00 & 0.01 & 0.03 & 0.03 & 0.08 & 0.19 & 0.27 & 0.21 & 0.06 \\
\hline
\end{tabular}

uma eventual impossibilidade de atendimento à demanda total pelo sistema. As prioridades de atendimento estabelecidas para o sistema foram: 1, 5 e 10, para as demandas de abastecimento, irrigação das culturas perenes e irrigação das culturas sazonais, respectivamente; as demandas hídricas mensais para a irrigação das culturas selecionadas estão mostradas na Tabela 6.

\section{RESULTADOS E DISCUSSÃO}

Culturas selecionadas, alocação de áreas e receita líquida

Das catorze culturas inicialmente previstas para o perímetro e se considerando plantio na safra e entressafra, o modelo de otimização selecionou sete culturas, sendo quatro culturas sazonais e as três culturas perenes previstas inicialmente; apenas a cultura de tomate foi prevista para o plantio na safra (sequeiro) e na entressafra (irrigado), conforme apresentado na Tabela 7.

Tabela 7. Culturas selecionadas e áreas alocadas

\begin{tabular}{|c|c|c|c|c|c|c|c|}
\hline & \multicolumn{4}{|c|}{ Sazonais } & \multicolumn{3}{|c|}{ Perenes } \\
\hline & Algodão & Milho & Melancia & Tomate & Banana & Graviola & Coco \\
\hline $\begin{array}{l}\text { Áreas } \\
\text { alocadas }\end{array}$ & 84 & 50 & 50 & $50 / 50$ & 50 & 50 & 550 \\
\hline $\begin{array}{l}\text { Época de } \\
\text { plantio** }\end{array}$ & ES & $\mathrm{ES}$ & ES & $S / E S$ & Cont. & Cont. & Cont. \\
\hline
\end{tabular}

* ES - plantio na entressafra; S - plantio na safra; Cont. - plantio contínuo

Segundo a alocação das áreas para as culturas perenes e sazonais para o perímetro Gravatá, apresentadas na Tabela 7, o modelo de otimização calculou, com base nos dados agronômicos e de mercado das culturas, uma receita líquida anual auferida com a agricultura irrigada, de R\$ 6.722.760,00; esses resultados tiveram como base um horizonte temporal de um ano, com dados climáticos médios de vazões afluentes aos reservatórios e de precipitação sobre a área do perímetro irrigado.

\section{Sustentabilidade hídrica do sistema de reservatórios}

Para verificar se o sistema hídrico dos reservatórios poderia manter as áreas irrigadas apresentadas na Tabela 7 para uma série maior de anos, realizaram-se simulações para análises da sustentabilidade hídrica dos reservatórios para o atendimento às demandas requeridas; para tanto, lançou-se mão do modelo de simulação ModSim P32 fazendo-se uso da série total de 57 anos de dados de vazões afluentes. Os resultados obtidos pelo estudo, segundo o enfoque (tipo de cálculo) e cenários estabelecidos (definidos anteriormente), foram:

- Simulação contínua: Nesta simulação, os reservatóri- os atenderam às demandas com garantia de 100\%. A operação dos reservatórios estabelecida pelo modelo foi de utilizar o volume total disponível açude Canoas, enquanto o reservatório Saco de Nova Olinda foi operado priorizando a demanda de abastecimento, suplementando as demandas hídricas de irrigação do perímetro.

- Planejamento tático: Nesta simulação, o modelo demonstrou a existência de sustentabilidade hídrica dos reservatórios no atendimento das demandas do sistema, sendo observada uma probabilidade acentuada do açude Canoas atingir seu nível mínimo ao final do $2^{\circ}$ ano do horizonte de planejamento. Esse fato é decorrente da política adotada pelo modelo, observada na simulação contínua, visto que o referido reservatório não atende a outras demandas podendo, portanto, ser utilizado todo o potencial hídrico para a irrigação.

- Cenários climáticos e volumes iniciais: Realizaram-se diversas simulações considerando-se os cenários climáticos, volumes iniciais nos reservatórios e horizontes de planejamento, obtendo-se os seguintes resultados:

1. Para o cenário climático seco e horizonte de planejamento de um ano: Neste cenário, a simulação mostrou que os reservatórios atenderiam às demandas do sistema, com os volumes iniciais de $30 \%$ de suas capacidades máximas.

2. Para o horizonte de planejamento de dois anos: Neste mesmo cenário climático foram realizadas simulações para condições hídricas de volumes inicias dos reservatórios de 30 e $40 \%$ das suas capacidades; os resultados estão apresentados na Tabela 8.

Os resultados apresentados na Tabela 8 demonstraram que, de maneira geral, com volumes iniciais de até 30\% das respectivas capacidades os reservatórios não teriam

Tabela 8. Volumes iniciais nos reservatórios e demandas atendidas pelo sistema, para o horizonte de planejamento de dois anos consecutivos secos

\begin{tabular}{|c|c|c|c|c|c|c|}
\hline \multirow{3}{*}{$\begin{array}{l}\text { Condição } \\
\text { hídrica }\end{array}$} & \multirow{3}{*}{ Resenvatório } & \multirow{2}{*}{\multicolumn{2}{|c|}{$\begin{array}{l}\text { Volumes iniciais nos } \\
\text { resenvatórios }\end{array}$}} & \multicolumn{3}{|c|}{ Atendimento as demandas } \\
\hline & & & & \multirow{2}{*}{$\begin{array}{c}\text { Abasteci- } \\
\text { mento } \\
\text { humano }\end{array}$} & \multirow{2}{*}{$\begin{array}{l}\text { Irrigação } \\
\text { perene }\end{array}$} & \multirow{2}{*}{$\begin{array}{l}\text { Irrigação } \\
\text { sazonal }\end{array}$} \\
\hline & & $\left(\mathrm{hm}^{3}\right)$ & $(\%)$ & & & \\
\hline \multirow[t]{2}{*}{1} & Canoas & 3,0 & 30,0 & & & \\
\hline & $\begin{array}{l}\text { Saco de } \\
\text { N. Olinda }\end{array}$ & 30,0 & 30,0 & Não & Não & Não \\
\hline \multirow[t]{2}{*}{2} & Canoas & 4,0 & 40,0 & & & \\
\hline & $\begin{array}{l}\text { Saco de } \\
\text { N. Olinda }\end{array}$ & 40,0 & 40,0 & Sim & Sim & Não \\
\hline \multirow[t]{2}{*}{3} & Canoas & 3,0 & 30,0 & & & \\
\hline & $\begin{array}{l}\text { Saco de } \\
\text { N. Olinda }\end{array}$ & 40,0 & 40,0 & $\operatorname{Sim}$ & $\operatorname{Sim}$ & Não \\
\hline \multirow[t]{2}{*}{4} & Canoas & 4,0 & 40,0 & & & \\
\hline & $\begin{array}{l}\text { Saco de } \\
\text { N. Olinda }\end{array}$ & 30,0 & 30,0 & $\operatorname{Sim}$ & $\operatorname{Sim}$ & Não \\
\hline
\end{tabular}

R. Bras. Eng. Agríc. Ambiental, v.12, n.2, p.157-165, 2008. 
sustentabilidade hídrica para o atendimento às demandas do perímetro irrigado Gravatá (condição hídrica 1). As demais condições hídricas apresentadas na referida tabela mostraram falhas no atendimento a demandas das culturas sazonais, decorrentes da menor prioridade atribuídas a estas; nesta condição, as demandas hídricas totais do sistema somente seriam supridas com a conclusão do reservatório Canoas, para sua capacidade de projeto, 45,655 $\mathrm{hm}^{3}$. Entretanto, mesmo considerando o referido reservatório na capacidade atual $\left(10 \mathrm{hm}^{3}\right)$, o sistema teria sustentabilidade hídrica nas condições de volumes iniciais estabelecidas em 2, 3 e 4 para o atendimento às demandas prioritárias (abastecimento urbano e irrigação das culturas perenes), condição para que a receita líquida anual advinda da agricultura irrigada seria em torno de $\mathrm{R} \$$ 5.401.850,00.

Ressalta-se, para a condição hídrica 4, que o volume final observado nos reservatórios foi inferior ao estabelecido como volume de alerta, de $20 \mathrm{hm}^{3}$; desta forma, o sistema atenderia às demandas prioritárias para o horizonte de dois anos; entretanto, correria o risco de repetir o processo, ou seja, não atender às referidas demandas, caso fosse verificado um cenário climático seco no ano seguinte. Para o horizonte de planejamento de dois anos foram simulados cenários climáticos alternados: um ano seco seguido de um ano normal (1) e um ano normal seguido de um ano seco (2); em ambas as situações foram realizadas simulações dos reservatórios nas condições de volumes iniciais de 30\% de suas capacidades; nessas simulações se considerou, como condição de sustentabilidade hídrica do sistema, quando o seu volume foi superior ao inicial, de forma a garantir que o processo seja repetido para as mesmas condições e por igual período de planejamento. Os resultados de volumes finais do sistema obtidos pela simulação para os cenários climáticos secos e alternados e horizontes de planejamento de 1 e 2 anos, estão apresentados na Tabela 9.

Tabela 9. Volumes nos reservatórios $\left(\mathrm{hm}^{3}\right)$ nos cenários e situações hídricas estudadas

\begin{tabular}{|c|c|c|c|c|c|c|}
\hline \multirow{2}{*}{$\begin{array}{l}\text { Horizontes de } \\
\text { planejamento }\end{array}$} & \multicolumn{2}{|c|}{$\begin{array}{c}\text { Ano seco e } \\
\text { ano normal (1) }\end{array}$} & \multicolumn{2}{|c|}{$\begin{array}{l}\text { Ano normal e } \\
\text { ano seco (2) }\end{array}$} & \multicolumn{2}{|c|}{$\begin{array}{l}\text { Vol. totais finais } \\
\text { nos reservatórios }\end{array}$} \\
\hline & Canoas & Saco & Canoas & Saco & (1) & (2) \\
\hline 1 ano & 0.50 & 17.44 & 0.79 & 57.36 & 17.94 & 58.15 \\
\hline 2 anos & 0.79 & 46.33 & 0.49 & 40.67 & 47.12 & 41.16 \\
\hline
\end{tabular}

Os resultados apresentados na Tabela 9 mostraram que o sistema de reservatórios teria sustentabilidade hídrica para o atendimento às demandas prioritárias e também das culturas sazonais (demandas totais), para o horizonte de planejamento de dois anos, nos cenários climáticos alternados, independente da ordem de acontecimento, ou seja, um ano seco seguido de um ano normal ou vice-versa; entretanto, para o cenário climático seco seguido de normal observouse, ao final do $1^{\circ}$ ano (mês de dezembro), o volume final do sistema inferior ao volume de alerta estabelecido para os reservatórios.

Outra observação pode ser feita com relação aos volumes finais no sistema de reservatórios, isto é, para o cenário cli- mático (1), o volume final foi inferior em $40,21 \mathrm{hm}^{3}$ no $1^{\mathrm{o}}$ ano de planejamento e superior em $5,96 \mathrm{hm}^{3}$ no $2^{\circ}$ ano de planejamento, em relação ao cenário climático (2). Este fato demonstra o efeito da ordem de acontecimento do cenário climático no qual, iniciando-se a simulação no cenário climático seco, observou-se um decréscimo no volume final do sistema a ponto de atingir, no $1^{\circ}$ ano, um volume inferior ao de alerta, com pouca recuperação em relação à simulação, iniciando-se com o ano normal seguido de um ano seco.

Na Figura 3 estão representados os gráficos dos comportamentos hídricos dos reservatórios Canoas (3A) e Saco de Nova Olinda (3B), para os cenários climáticos e condições hídricas anteriormente descritas.
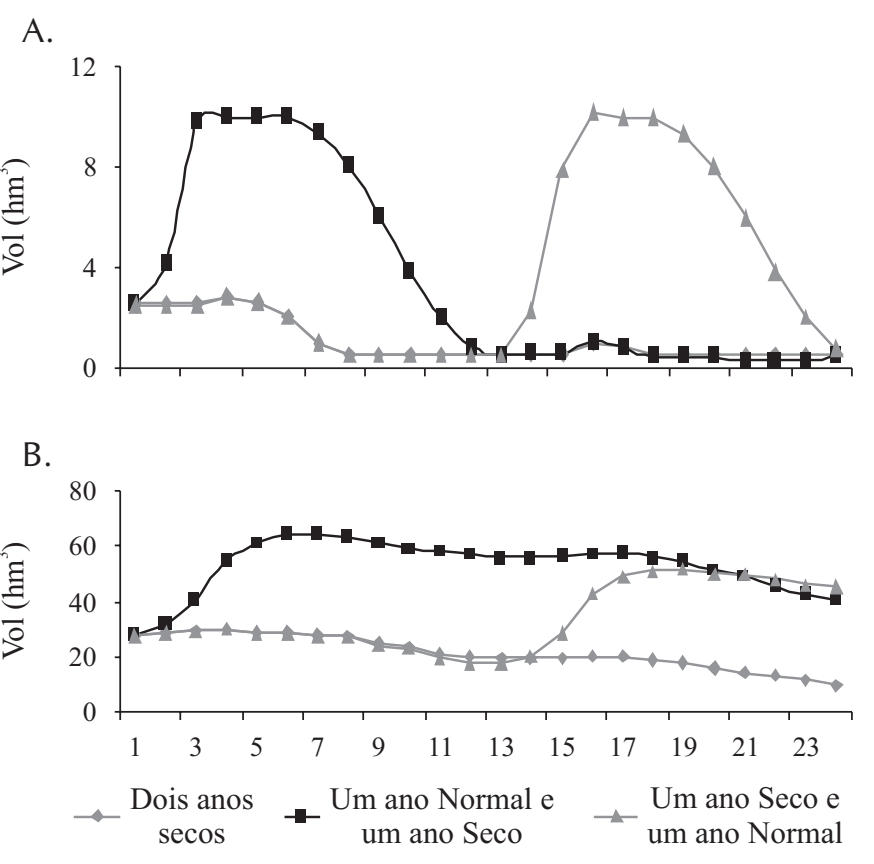

Figura 3. Comportamento hídrico dos reservatórios: (A) Canoas e (B) Saco de Nova Olinda

\section{CONCLUSÕES}

1. Existe grande possibilidade de reativação do perímetro irrigado Gravatá, sob o ponto de vista da sustentabilidade hídrica dos reservatórios, mesmo sem a conclusão do reservatório Canoas.

2. A utilização de modelos de alocação otimizada de água mostrou que é possível, mesmo em condições hidroclimáticas adversas e com baixos percentuais de água nos reservatórios, suprir as demandas hídricas primárias: abastecimento e irrigação, através de estabelecimento de políticas operacionais para os reservatórios e estabelecimento de prioridades de atendimento às demandas.

3. Constatou-se que é possível, com a adoção das mudanças no plano de cultivo e do sistema de irrigação propostas, gerar receitas atrativas com a reativação do perímetro.

4. Constatou-se, com relação à sustentabilidade hídrica dos reservatórios que, para os volumes iniciais de 30\% no reservatório Canoas e de 40\% no reservatório Saco de Nova 
Olinda, seria possível suprir as demandas primárias, incluídas às demandas para as culturas perenes, que ocupam $70 \%$ da área potencial do perímetro, gerando uma receita líquida anual de $\mathrm{R}$ \$ 5,4 milhões de reais.

5. Os benefícios diretos e indiretos, decorrentes da atividade da agricultura irrigada, justificariam a reativação do perímetro irrigado Gravatá, visto que o mesmo proporcionaria grande desenvolvimento socioeconômico para a região do Vale do Piancó.

\section{LITERATURA CITADA}

Curi, W. F.; Curi, R. C. ORNAP - Optimal reservoir network analysis program. In: Simpósio de Hidráulica e Recursos Hídricos dos Países de Língua Oficial Portuguesa, 5, 2001, Aracaju. Anais... Aracaju: ABRH, 2001, CD Rom

Gomes, H. P. Engenharia de irrigação hidráulica dos sistemas pressorizados, aspersão e gotejamento. 3.ed. Campina Grande: UFPB, 1999. 412p.
Labadie, J. W. MODSIM: Modelo de rede de fluxo para simulação de bacias hidrográficas, 1989. http://www.phd.poli.usp.br/ phd/pos. 23 Abr. 2003.

Lanna, A. E. Análise de sistemas e engenharia de recursos hídricos. In: Técnicas Quantitativas para o Gerenciamento de Recursos Hídricos. Porto Alegre: UFRGS/ABRH, 1997, p.15-41.

Lima, C. A. G. Análise e sugestão para diretrizes de uso das disponibilidades hídricas superficiais da bacia hidrográfica do rio Piancó, localizada no Estado da Paraíba. Campina Grande: UFCG, 2004. 274p. Tese Doutorado

SCIENTEC - Associação para Desenvolvimento da Ciência e Tecnologia. Plano diretor de recursos hídricos da Paraíba: Bacias do Rio Piancó e do Alto Piranhas. João Pessoa: SEPLAN, t.1, v.1, 1997, p.120-130.

Silva, W. P.; Silva, C. P. Software de ajuste de curvas, 2003. http:/ /zeus.df.ufcg.br/laffit p.htm. 25 Mai. 2005.

Vieira, V. P. P. B. Recursos hídricos e o desenvolvimento sustentável do Semi-Árido nordestino. Revista Brasileira de Recursos Hídricos, v.1, n.1, p.92-98, 1996. 